\title{
Validation of the Performance of International Ovarian Tumor Analysis (IOTA) Methods in the Diagnosis of Early Stage Ovarian Cancer in a Non-Screening Population
}

\author{
Wouter Froyman ${ }^{1,2}$, Laure Wynants ${ }^{1}$, Chiara Landolfo ${ }^{1,2}$, Tom Bourne ${ }^{1,2,3}$, Lil Valentin ${ }^{4}$, \\ Antonia Testa ${ }^{5}$, Povilas Sladkevicius ${ }^{4}$, Dorella Franchi ${ }^{6}$, Daniela Fischerova ${ }^{7}$, Luca Savelli ${ }^{8}$, \\ Ben Van Calster ${ }^{1}$ and Dirk Timmerman ${ }^{1,2, *}$ \\ 1 Department of Development and Regeneration, KU Leuven, Leuven post code3000, Belgium; \\ wouter.froyman@uzleuven.be (W.F.); laure.wynants@kuleuven.be (L.W.); \\ chiara.landolfo@kuleuven.be (C.L.); t.bourne@imperial.ac.uk (T.B.); ben.vancalster@kuleuven.be (B.V.C.) \\ Department of Obstetrics and Gynecology, University Hospitals Leuven, Leuven 3000, Belgium \\ Queen Charlotte's and Chelsea Hospital, Imperial College, London W12 0HS, UK \\ 4 Department of Obstetrics and Gynecology, Skåne University Hospital Malmö, Lund University, \\ Malmö 20502, Sweden; lil.valentin@med.lu.se (L.V.); povilas.sladkevicius@med.lu.se (P.S.) \\ 5 Department of Oncology, Catholic University of the Sacred Heart, Rome 00168, Italy; atesta@rm.unicatt.it \\ 6 Preventive Gynecology Unit, Division of Gynecology, European Institute of Oncology, Milan 20141, Italy; \\ dorella.franchi@ieo.it \\ 7 Gynecological Oncology Center, Department of Obstetrics and Gynecology, Charles University, \\ Prague 12108, Czech Republic; Daniela.Fischerova@seznam.cz \\ 8 Department of Obstetrics and Gynecology, S. Orsola-Malpighi Hospital, University of Bologna, \\ Bologna 40138, Italy; luca.savelli@aosp.bo.it \\ * Correspondence: dirk.timmerman@uzleuven.be; Tel.: +32-16-3-44201 or +32-16-3-44216
}

Academic Editor: Edward J. Pavlik

Received: 28 March 2017; Accepted: 26 May 2017; Published: 2 June 2017

\begin{abstract}
Background: The aim of this study was to assess and compare the performance of different ultrasound-based International Ovarian Tumor Analysis (IOTA) strategies and subjective assessment for the diagnosis of early stage ovarian malignancy. Methods: This is a secondary analysis of a prospective multicenter cross-sectional diagnostic accuracy study that included 1653 patients recruited at 18 centers from 2009 to 2012. All patients underwent standardized transvaginal ultrasonography by experienced ultrasound investigators. We assessed test performance of the IOTA Simple Rules (SRs), Simple Rules Risk (SRR), the Assessment of Different NEoplasias in the adneXa (ADNEX) model and subjective assessment to discriminate between stage I-II ovarian cancer and benign disease. Reference standard was histology after surgery. Results: 230 (13.9\%) patients proved to have stage I-II primary invasive ovarian malignancy, and 1423 (86.1\%) had benign disease. Sensitivity and specificity with respect to malignancy ( $95 \%$ confidence intervals) of the original SRs (classifying all inconclusive cases as malignant) were $94.3 \%(90.6 \%$ to $96.7 \%)$ and $73.4 \%(71.0 \%$ to $75.6 \%$ ). Subjective assessment had a sensitivity and specificity of $90.0 \%$ (85.4\% to $93.2 \%)$ and $86.7 \%$ $(84.9 \%$ to $88.4 \%)$, respectively. The areas under the receiver operator characteristic curves of SRR and ADNEX were 0.917 (0.902 to 0.933) and 0.905 (0.920 to 0.934), respectively. At a 1\% risk cut-off, sensitivity and specificity for SRR were $100 \%$ (98.4\% to $100 \%)$ and $38.0 \%$ (35.5\% to $40.6 \%$ ), and for ADNEX were $100 \%$ (98.4\% to $100 \%)$ and $19.4 \%$ (17.4\% to $21.5 \%)$. At a $30 \%$ risk cut-off, sensitivity and specificity for SRR were $88.3 \%$ (83.5\% to $91.8 \%$ ) and $81.1 \%$ (79\% to $83 \%)$, and for ADNEX were $84.5 \%(80.5 \%$ to $89.6 \%)$ and $84.5 \%$ (82.6\% to $86.3 \%)$. Conclusion: This study shows that all three IOTA strategies have good ability to discriminate between stage I-II ovarian malignancy and benign disease.
\end{abstract}


Keywords: ovary; ovarian neoplasms; early detection of cancer; diagnostic imaging; ultrasonography; risk assessment; logistic models

\section{Introduction}

Ovarian tumors are common in women of all ages [1-3]. It has been estimated that in the female population, the lifetime risk of undergoing surgery for a suspected ovarian neoplasm is $5-10 \%$ [4]. However, the incidence of ovarian cancer is low. In Europe, there were 65,538 new cases during 2012, with an age-adjusted incidence rate of 13.1 per 100,000 women. Still, ovarian cancer is an important health problem in gynecology, as it is the most lethal gynecological malignancy, with 42,700 deaths occurring in 2012 in Europe (mortality rate 7.6 per 100,000) [5]. This accounts for 5\% of all cancer deaths in women, which makes ovarian cancer the sixth most lethal cancer in females in Europe [6].

In recent decades, despite advances in cytoreductive radical surgery and cytotoxic chemotherapy, we have seen only a marginal improvement in the overall survival of patients with ovarian cancer [7].

Almost $60 \%$ of patients are diagnosed with advanced disease with regional or distant spread and an unfavorable long-term prognosis. Five-year relative survival is $46 \%$ for all International Federation of Gynecology and Obstetrics (FIGO) stages [8], but ranges from $90 \%$ at Stage I to $4 \%$ for Stage IV disease $[6,8]$. Therefore, attention for the development of strategies to detect ovarian malignancy at an early stage using imaging and/or biomarkers is increasing, in order to improve patient survival. This idea is reflected in the conduction of several large ovarian cancer screening trials [9-11], but also plays an important role in clinical management of the non-screening population.

Early detection of cancer means that treatment is not delayed and that appropriate staging can be carried out in specialized surgical centers, which is known to improve survival [12-15].

The best ultrasound method for discrimination between benign and malignant adnexal masses is the subjective assessment of ultrasound findings by an experienced ultrasound examiner [16-18]. However, as such expert knowledge is not available in each center, the International Ovarian Tumor Analysis (IOTA) study aims to develop diagnostic algorithms to assist clinicians in characterizing adnexal pathology, irrespective of their level of expertise. The IOTA group initially published a consensus paper in order to standardize terms, definitions, and measurements used to assess ovarian pathology [19]. By prospectively investigating patients presenting with an adnexal mass (i.e., non-screening population), this formed the basis for the development of different IOTA methods such as the Simple Rules (SRs), which are based on five ultrasound features suggestive for a benign lesion (B-features) and five features suggestive for a malignant lesion (M-features) [20]. The IOTA SRs have become very popular because they are easy to use, without the need for any calculation. They have been extensively validated and are incorporated in international guidelines [21,22]. Two systematic reviews and meta-analyses have concluded that the IOTA SRs are one of the best performing available diagnostic methods for differentiating between benign and malignant adnexal masses $[18,23]$. Shortcomings of the SRs are that there are inconclusive results in a proportion of cases (when B and $\mathrm{M}$ features apply or when no features apply) and the absence of an estimated risk of malignancy. Therefore, the ultrasound features used in the SRs have recently been used to calculate a risk of malignancy, leading to the Simple Rules Risk (SRR) model [24]. Another logistic regression model developed by the IOTA group is the Assessment of Different NEoplasias in the adneXa (ADNEX) model. As a multiclass prediction model, ADNEX not only calculates the likelihood of malignancy in adnexal masses, but also divides this into the likelihood that the mass is borderline malignant, stage I primary invasive ovarian cancer, stage II-IV primary invasive ovarian cancer, or a metastasis in the ovary from another primary tumor [25]. The performance of ADNEX is at least as good as the performance of previous IOTA methods, as confirmed by external validation studies [26-30]. The ADNEX model is available online and in mobile applications (www.iotagroup.org/adnexmodel/). 
Given the good performance of IOTA strategies in discriminating between benign and malignant disease in patients presenting with an adnexal mass prior to surgery, we are often confronted with the question on how IOTA methods could potentially improve detection in ovarian cancer screening. For the purpose of this special issue of Diagnostics, we assessed and compared the test performance of various diagnostic IOTA methods and subjective assessment to identify early stage, i.e., FIGO stage I and II [8], primary invasive ovarian malignancy in a non-screening population.

\section{Materials and Methods}

\subsection{Patients}

This study was performed on data of IOTA phase 3 [31], a multicenter cross-sectional diagnostic accuracy study with prospective data collection. Patients were recruited in 18 centers in six countries (Sweden, Belgium, Italy, Poland, Spain, and Czech Republic) between October 2009 and May 2012. The participating centers were either oncology referral centers (i.e., tertiary centers with a specific gynecological oncology unit) or general hospitals and units with a special interest in gynecological ultrasound. Ethics approval for IOTA 3 was obtained by the ethics committee of the University Hospitals Leuven (B32220095331/S51375 approved 21 January 2009) as the main investigating center as well of the local ethics committees of all contributing centers.

Patients were eligible for IOTA 3 if they presented with at least one adnexal mass (ovarian, para-ovarian, or tubal), underwent standardized transvaginal ultrasonography by a principal investigator at one of the participating centers, and were then selected for surgical intervention by the managing clinician. All examiners were experienced in gynecologic ultrasound. Details on the ultrasound examination technique and the IOTA terms and definitions used to describe adnexal pathology have been published elsewhere [19]. More information on data collection can be found in the original IOTA 3 publication [31]. The pathologist was blinded to the predicted outcomes of the index tests being compared.

For the purpose this study, only patients having a histopathology diagnosis of a benign mass or FIGO stage I and II [8] invasive (epithelial or non-epithelial) ovarian malignancy were considered for analysis.

\subsection{Diagnostic Models}

Three diagnostic IOTA methods for the assessment of adnexal masses (the original SRs, SRR and ADNEX) were evaluated in terms of their ability to discriminate between benign disease and stage I-II primary ovarian malignancy. These methods were developed on data of earlier IOTA phases. Hence, this is a temporal validation study, including new centers. The original IOTA SRs result in a classification of ovarian masses as benign, malignant, or inconclusive. In this work, we classified inconclusive cases as malignant. The SRR yields a predicted probability of ovarian malignancy. The ADNEX model provides the predicted risks of four different subclasses of malignant adnexal tumors (borderline, stage I invasive, stage II-IV invasive or metastatic cancer). When using the ADNEX model, the probability of malignancy is computed as the sum of the predicted probabilities for all malignant subtypes (including borderline tumors). We validated the version of ADNEX that does not use serum cancer antigen 125 (CA125) measurements as a predictor, because CA125 results are not always available in women with benign or stage I-II tumors (results for serum CA125 measurements were missing for $45 \%$ of women in our database). ADNEX with and without CA125 has similar ability to predict malignancy [25]. Both SRR and ADNEX were initially developed on data from IOTA phases 1 and 2, validated on data from IOTA 3, and then refitted on all data [24,25]. In this study, we used the initial versions of SRR and ADNEX that were not refitted using IOTA 3 data. We also evaluated the performance of subjective assessment. 


\subsection{Statistical Methods}

All strategies were evaluated in terms of their ability to discriminate between benign and malignant masses. The area under the receiver-operator characteristic curve (AUC) was computed for ADNEX and the SRR. We also calculated the sensitivity and specificity for ADNEX and the SRR at risk thresholds of $1 \%, 10 \%, 20 \%$, and $30 \%$, as well the sensitivity and specificity of the original SRs (classifying inconclusive results as malignant) and subjective assessment. Subgroup analyses were performed for pre- and postmenopausal women. R software (version 3.3.1.) was used for all calculations (R: A language and environment for statistical computing. R Foundation for Statistical Computing, Vienna, Austria, Available online: http/www.r-project.org/). The pROC package and binom packages were used to calculate Delong [32] and Wilson [33] confidence intervals for AUCs and sensitivity/specificity, respectively. The Transparent Reporting of a multivariable prediction model for Individual Prognosis or Diagnosis (TRIPOD) guidelines [34] were used for reporting in this study.

\section{Results}

In total, 2541 women with adnexal masses were enrolled in IOTA phase 3 . We excluded 138 women from the final data set after the application of exclusion criteria [31].

Of the remaining 2403 patients, 1423 had a benign mass. Patients with borderline tumors, stage III-IV primary invasive malignancies, and metastatic cancer were excluded from the analysis. The resulting database for analysis consisted of 1653 women from 18 centers, 230 of which had stage I-II invasive ovarian malignancy. Patient and tumor characteristics are represented in Table 1. Of the women included, $34.6 \%$ were postmenopausal. Histology findings are listed in Table 2.

Table 1. Descriptive statistics of the sample.

\begin{tabular}{lcc}
\hline \multicolumn{1}{c}{ Variable } & \multicolumn{2}{c}{ Result } \\
\cline { 2 - 3 } & Benign Tumor & Early Stage Malignancy (I and II) \\
\hline$N$ & $1423(86.1 \%)$ & $230(13.9 \%)$ \\
Age (years) & $44(33$ to 56$)$ & $55(42$ to 66$)$ \\
Postmenopausal & $447(31.4 \%)$ & $125(54.3 \%)$ \\
CA125 (IU /L), if available a & $21(12$ to 46$)$ & $55(20$ to 207$)$ \\
Maximum tumor diameter (mm) & $64(47$ to 90$)$ & $103(68$ to 143$)$ \\
Presence of solid components & $474(33.3 \%)$ & $214(93.0 \%)$ \\
Maximum diameter of the solid component (if any, mm) & $28(13$ to 54$)$ & $62(37$ to 93$)$ \\
Locularity & & \\
Unilocular & $595(41.8 \%)$ & $2(0.9 \%)$ \\
Unilocular-solid & $141(9.9 \%)$ & $34(14.8 \%)$ \\
Multilocular & $354(24.9 \%)$ & $14(6.1 \%)$ \\
Multilocular-solid & $179(12.6 \%)$ & $93(40.4 \%)$ \\
Solid & $154(10.8 \%)$ & $87(37.8 \%)$ \\
Number of locules (if any) & $1(1$ to 3$)$ & $5(1.5$ to 6$)$ \\
Acoustic shadows & $265(18.6 \%)$ & $17(7.4 \%)$ \\
Intratumoral blood flow & & \\
No blood flow & $574(40.3 \%)$ & $5(2.2 \%)$ \\
Minimal blood flow & $563(39.6 \%)$ & $54(23.5 \%)$ \\
Moderate blood flow & $239(16.8 \%)$ & $95(41.3 \%)$ \\
Very strong blood flow & $47(3.3 \%)$ & $76(33.0 \%)$ \\
Irregular internal cyst wall & $385(27.1 \%)$ & $151(65.7 \%)$ \\
Presence of ascites & $18(1.3 \%)$ & $33(14.3 \%)$ \\
Presence of papillary structures & $180(12.6 \%)$ & $54(23.5 \%)$ \\
Number of papillary structures (if present) & $1(1$ to 3$)$ & $3(2$ to 4$)$ \\
\hline a CA125: cancer antigen 125. There were 683 (48\%) missing values for CA125 for benign tumors and 64 (28\%) for \\
$\quad$ early stage tumors. & & \\
& &
\end{tabular}

Results are shown as medians (interquartile range) for continuous and ordinal variables, and as $N$ (\%) for categorical variables. Possible values for "Number of locules" are $1=$ presence of one locule, 
$2=$ presence of two locules, $3=$ presence of three locules, $4=$ presence of four locules, $5=$ presence of five to ten locules, $6=$ presence of more than ten locules. Possible values for "Number of papillary structures" are $1=$ presence of one papillary structure, $2=$ presence of two papillary structures, $3=$ presence of three papillary structures, $4=$ presence of more than three papillary structures.

Table 2. Overview of histologic outcomes $(N, \%)$.

\begin{tabular}{cc}
\hline Histology & $N \mathbf{( \% )}$ \\
\hline Endometrioma & $344(20.8 \%)$ \\
Teratoma & $231(14.0 \%)$ \\
Simple cyst + parasalpingeal cyst & $106(6.4 \%)$ \\
Functional cyst & $40(2.4 \%)$ \\
Hydrosalpinx + salpingitis & $47(2.8 \%)$ \\
Peritoneal pseudocyst & $18(1.1 \%)$ \\
Abscess & $17(1.0 \%)$ \\
Fibroma & $130(7.9 \%)$ \\
Serous cystadenoma & $259(15.7 \%)$ \\
Mucinous cystadenoma & $183(11.1 \%)$ \\
Rare benign & $48(2.9 \%)$ \\
Primary invasive (epithelial) cancer stage I & $128(7.7 \%)$ \\
Primary invasive (epithelial) cancer stage II & $47(2.8 \%)$ \\
Rare primary invasive malignancy stage I or II * & $55(3.3 \%)$ \\
\hline * Includes germ cell tumors and sex cord-stromal tumors.
\end{tabular}

Regarding the identification of stage I-II primary ovarian malignancy as malignant disease, the original SRs (classifying inconclusive cases as malignant) had a sensitivity and specificity ( $95 \%$ confidence intervals) of $94.3 \%$ (90.6\% to $96.7 \%$ ) and $73.4 \%(71.0 \%$ to $75.6 \%)$. Subjective assessment had a sensitivity and specificity of $90.0 \%$ (85.4\% to $93.2 \%)$ and $86.7 \%(84.9 \%$ to $88.4 \%)$, respectively. Considering the discrimination of benign and malignant disease in the study population of patients with benign masses and stage I-II primary ovarian malignancy the AUCs of the SRR and ADNEX model were 0.917 (0.902 to 0.933 ) and 0.920 (0.905 to 0.934 ), respectively. The sensitivity and specificity for these risk prediction models differ depending on the selected risk threshold to predict malignancy. Table 3 summarizes the sensitivity and specificity for the two models at different risk thresholds.

Table 3. Sensitivity and specificity for Assessment of Different NEoplasias in the adneXa (ADNEX) model and Simple Rules Risk (SRR) model at various risk thresholds (percent (95\% confidence interval)).

\begin{tabular}{cccc}
\hline Risk Threshold & Statistic & ADNEX & SRR \\
\hline \multirow{2}{*}{$1 \%$} & Sensitivity & $100.0 \%$ & $100.0 \%$ \\
& & $(98.4 \%$ to $100.0 \%)$ & $(98.4 \%$ to $100.0 \%)$ \\
& Specificity & $19.4 \%$ & $38.0 \%$ \\
& & $(17.4 \%$ to $21.5 \%)$ & $(35.5 \%$ to $40.6 \%)$ \\
& Sensitivity & $97.4 \%$ & $97.0 \%$ \\
$10 \%$ & & $(94.4 \%$ to $98.8 \%)$ & $(93.9 \%$ to $98.5 \%)$ \\
& Specificity & $69.5 \%$ & $65.1 \%$ \\
& & $(67.1 \%$ to $71.8 \%)$ & $(62.6 \%$ to $67.6 \%)$ \\
& Sensitivity & $91.3 \%$ & $94.3 \%$ \\
& & $(87.0 \%$ to $94.3 \%)$ & $(90.6 \%$ to $96.7 \%)$ \\
& Specificity & $79.7 \%$ & $74.3 \%$ \\
& & $(77.5 \%$ to $81.7 \%)$ & $(71.9 \%$ to $76.5 \%)$ \\
& Sensitivity & $84.5 \%$ & $88.3 \%$ \\
& & $(80.5 \%$ to $89.6 \%)$ & $(83.5 \%$ to $91.8 \%)$ \\
$30 \%$ & Specificity & $84.5 \%$ & $81.1 \%$ \\
& & $(82.6 \%$ to $86.3 \%)$ & $(79.0 \%$ to $83.0 \%)$ \\
\hline
\end{tabular}

When stratifying for menopausal status, the original SRs (classifying inconclusive cases as malignant) had a sensitivity and specificity of $94.3 \%(88.1 \%$ to $97.4 \%)$ and $77.3 \%$ (74.5\% to $79.8 \%)$ in 
premenopausal patients, and $94.4 \%(88.9 \%$ to $97.3 \%)$ and $64.9 \%(60.3 \%$ to $69.2 \%)$ in postmenopausal patients. Subjective assessment had a sensitivity and specificity of $87.6 \%(80.0 \%$ to $92.6 \%)$ and $89.0 \%$ $(86.9 \%$ to $90.8 \%)$ in premenopausal patients, and $92.0 \%(85.9 \%$ to $95.6 \%)$ and $81.7 \%(77.8 \%$ to $85.0 \%)$ in postmenopausal patients.

In premenopausal women, the AUCs of the SRR and ADNEX model were 0.932 (0.913 to 0.950) and 0.932 (0.913 to 0.950$)$, respectively. In postmenopausal women, the AUCs of the SRR and ADNEX model were 0.882 (0.853 to 0.912 ) and 0.885 (0.858 to 0.912 ), respectively.

Table 4 summarizes the sensitivity and specificity for the two models at different risk thresholds for pre- and postmenopausal women.

Table 4. Sensitivity and specificity by menopausal status for Assessment of Different NEoplasias in the adneXa (ADNEX) model and Simple Rules Risk (SRR) model at various risk thresholds (percent (95\% confidence interval)).

\begin{tabular}{cccccc}
\hline \multirow{2}{*}{$\begin{array}{c}\text { Risk } \\
\text { Threshold }\end{array}$} & \multirow{2}{*}{ Statistic } & \multicolumn{2}{c}{ ADNEX } & \multicolumn{2}{c}{ SRR } \\
\cline { 3 - 5 } & & Premenopausal & Postmenopausal & Premenopausal & Postmenopausal \\
\hline \multirow{2}{*}{$1 \%$} & Sens & $100.0 \%$ & $100.0 \%$ & $100.0 \%$ & $100 \%$ \\
& & $(96.5 \%$ to $100.0 \%)$ & $(97.0 \%$ to $100 \%)$ & $(96.5 \%$ to $100.0 \%)$ & $(97.0 \%$ to $100.0 \%)$ \\
& Spec & $25.8 \%$ & $5.4 \%$ & $41.4 \%$ & $30.6 \%$ \\
& & $(23.2 \%$ to $28.7 \%)$ & $(3.6 \%$ to $7.9 \%)$ & $(38.3 \%$ to $44.5 \%)$ & $(26.6 \%$ to $35.1 \%)$ \\
\multirow{2}{*}{$10 \%$} & Sens & $94.3 \%$ & $100 \%$ & $98.1 \%$ & $96.0 \%$ \\
& & $(88.1 \%$ to $97.4 \%)$ & $(97.0 \%$ to $100 \%)$ & $(93.3 \%$ to $99.5 \%)$ & $(91.0 \%$ to $98.3 \%)$ \\
& Spec & $77.8 \%$ & $51.5 \%$ & $70.6 \%$ & $53.2 \%$ \\
& & $(75.1 \%$ to $80.3 \%)$ & $(46.8 \%$ to $56.1 \%)$ & $(67.7 \%$ to $73.4 \%)$ & $(48.6 \%$ to $57.8 \%)$ \\
$20 \%$ & Sens & $(78.9 \%$ to $91.9 \%)$ & $(89.9 \%$ to $97.8 \%)$ & $(88.1 \%$ to $97.4 \%)$ & $(88.9 \%$ to $97.3 \%)$ \\
& & $85.6 \%$ & $66.9 \%$ & $78.5 \%$ & $65.1 \%$ \\
& Spec & $(83.2 \%$ to $87.6 \%)$ & $(62.4 \%$ to $71.1 \%)$ & $(75.8 \%$ to $80.9 \%)$ & $(60.6 \%$ to $69.4 \%)$ \\
& & $78.1 \%$ & $92.0 \%$ & $84.8 \%$ & $91.2 \%$ \\
$30 \%$ & Sens & $(69.3 \%$ to $84.9 \%)$ & $(85.9 \%$ to $95.6 \%)$ & $(76.7 \%$ to $90.4 \%)$ & $(84.9 \%$ to $95.0 \%)$ \\
& & $89.5 \%$ & $73.6 \%$ & $84.1 \%$ & $74.5 \%$ \\
& Spec & $(87.5 \%$ to $81.3 \%)$ & $(96.3 \%$ to $77.5 \%)$ & $(81.7 \%$ to $86.3 \%)$ & $(70.3 \%$ to $78.3 \%)$ \\
\hline
\end{tabular}

\section{Discussion}

This validation of IOTA ultrasound-based rules and risk prediction models showed good test performance to discriminate between benign disease and stage I-II ovarian malignancy before surgery.

The strength of this study is the use of a large international database in which information was prospectively collected using well-defined terms, definitions, and measurement methods [19]. The large sample size and the participation of different types of centers are likely to yield generalizable results.

A limitation of our study is that the diagnostic methods were validated exclusively on patients who underwent surgery. This does not reflect clinical practice, where some masses are managed expectantly, but it allowed us to use histological diagnosis as the gold standard. We are awaiting the results of IOTA phase 5 , in which IOTA methods are validated on consecutively collected adnexal masses of all kinds, including those managed conservatively. A second limitation is that all ultrasound examiners in the study were very experienced. Our results might not necessarily be applicable to less experienced operators. However, published studies have shown that the IOTA SRs and ADNEX retain their performance in the hands of less experienced examiners $[27,28,35-41]$. This is likely to be true also for the SRR model, because the same ultrasound variables are used in the original SRs are used to calculate the risks of the SRR model. A third limitation of our study is that not all histopathology information necessary to classify the tumors into type I and type II epithelial malignancies had been collected. This is explained by the fact that patient recruitment for IOTA 3 started in 2009, before the dualistic model of ovarian carcinogenesis [42] was widely accepted.

The findings of our study show that the performance of IOTA methods for differentiating benign disease from stage I-II primary ovarian malignancy is not much lower than the performance 
for the discrimination of benign from all malignant disease (all malignant subtypes grouped together) [24,25,31]. In the original publications including all IOTA 3 patients, validation AUCs (95\% confidence intervals) regarding discrimination between benign and malignant disease for SRR and ADNEX (without CA125) were 0.917 (0.902-0.930) [24] and 0.932 (0.922-0.941) [25], respectively. Sensitivity and specificity for the original SRs on validation in the same population were $95.3 \%(93.1 \%$ to $96.9 \%)$ and $74.1 \%(67.7 \%$ to $79.7 \%)$, respectively [24,25,31].

Borderline malignant tumors were excluded from our analysis. These tumors are known to be more difficult to classify as benign or malignant $[25,43,44]$. On the other hand, borderline (i.e., non-invasive malignant) ovarian tumors rarely precede invasive epithelial ovarian carcinoma [45,46]. More clinically relevant is the correct identification of early stage primary invasive tumors, where prompt and adequate surgical staging is important for improving survival [47]. Detection of stage I-II ovarian cancer is particularly important for screening for ovarian cancer to be successful. The aim of screening for ovarian cancer is to decrease ovarian cancer mortality. For this to be possible, screening should result in a shift towards earlier stages at detection, i.e., the detection rate of stage I-II ovarian cancer should be high. However, a shift towards earlier detection of ovarian cancer has been shown in only two $[9,11]$ of three randomized controlled trials [9-11] on ovarian cancer screening, and none of the two completed screening trials has shown conclusive evidence of decreased ovarian cancer mortality in the screened group [10,11]. In the two completed randomized trials on ovarian cancer screening $[10,11]$, the ultrasound criteria to define an abnormal screening result were subjective or arbitrary. As a result, many patients with benign disease were scheduled for surgery, i.e., a large number of operations were performed to detect one cancer case. We speculate that the positive predictive value of an abnormal screen result could be improved if the IOTA methods were used to define an abnormal scan result. To the best of our knowledge, the discriminative or predictive performance of the IOTA methods has never been assessed in a screening population.

About $90 \%$ of invasive malignant ovarian tumors are epithelial [48]. The dualistic model proposed by Shih and Kurman highlights the heterogeneity of ovarian carcinoma and implies that ultrasound-based screening will not be effective in detecting all types of ovarian carcinoma. Type I tumors (low-grade serous, low-grade endometrioid, clear cell, and mucinous) are slow growing, attain a large size while still confined to the ovary, and are thus likely to be detected early by transvaginal ultrasound. Unfortunately, these lesions constitute only $25 \%$ of ovarian cancers and account for only approximately $10 \%$ of ovarian cancer deaths. On the other hand, type II tumors (high-grade serous and undifferentiated carcinomas, and malignant mixed mesodermal tumors (carcinosarcomas)) represent $75 \%$ of all ovarian carcinomas, are responsible for $90 \%$ of ovarian cancer deaths, and may originate outside the ovary. These tumors are almost never confined to the ovary at diagnosis, making their diagnosis at an early point in the disease course challenging [42,49]. To allow detection of this aggressive type of ovarian cancer, there is ongoing search for sensitive biomarkers expressed early in ovarian carcinogenesis. More recently, there is increasing interest in the use of genomic profiling as a potential candidate for the detection of ovarian malignancies [50,51]. Further research should explore whether IOTA methods may serve as a second stage test in a program of ovarian cancer screening to avoid unnecessary surgery without delaying a diagnosis of ovarian cancer.

\section{Conclusions}

This analysis shows that the IOTA methods have good ability to discriminate between stage I-II ovarian malignancy and benign adnexal lesions prior to surgery. The potential use of IOTA methods as a second stage test in ovarian cancer screening should be the subject of further investigation.

Acknowledgments: This study was supported by the Flemish government (Research Foundation-Flanders (FWO) project G049312N and G0B4716N, Flanders' Agency for Innovation by Science and Technology (IWT) project IWT-TBM 070706-IOTA3, and iMinds 2015) and Internal Funds KU Leuven (University of Leuven) (project C24/15/037). Dirk Timmerman is a senior clinical investigator of Fonds Wetenschappelijk Onderzoek (FWO). Tom Bourne is supported by the National Institute for Health Research (NIHR) Biomedical Research Centre based at Imperial College Healthcare National Health Service (NHS) Trust and Imperial College London. 
The views expressed are those of the authors and not necessarily those of the NHS, NIHR or Department of Health, Lil Valentin is supported by the Swedish Medical Research Council (grants K2001-72X-11605-06A, K2002-72X-11605-07B, K2004-73X-11605-09A, and K2006-73X-11605-11-3), funds administered by Malmö University Hospital and Skåne University Hospital, Allmänna Sjukhusets i Malmö Stiftelse för bekämpande av cancer (the Malmö General Hospital Foundation for fighting against cancer), and two Swedish governmental grants (Avtal om läkarutbildning och forskning (ALF)-medel and Landstingsfinansierad Regional Forskning). Laure Wynants holds a postdoctoral mandate from Internal Funds KU Leuven. The sponsors had no role in study design; in the collection, analysis, and interpretation of data; in the writing of the report; and in the decision to submit the work for publication. The researchers performed this work independently of the funding sources.

Author Contributions: Wouter Froyman, Laure Wynants, Chiara Landolfo, Ben Van Calster and Dirk Timmerman conceived and designed the study, with additional support from Tom Bourne, Lil Valentin and Antonia Testa; Lil Valentin, Antonia Testa, Povilas Sladkevicius, Dorella Franchi, Daniela Fischerova, Luca Savelli and Dirk Timmerman enrolled patients and acquired data; Ben Van Calster and Dirk Timmerman were involved in data cleaning; Laure Wynants analyzed the data, with support from Ben Van Calster; Wouter Froyman, Laure Wynants, Chiara Landolfo, Tom Bourne, Lil Valentin, Antonia Testa, Ben Van Calster and Dirk Timmerman were involved in data interpretation; Wouter Froyman, Laure Wynants, Chiara Landolfo, Ben Van Calster and Dirk Timmerman wrote the first draft of the manuscript, which was then critically reviewed and revised by the other coauthors. All authors approved the final version of the manuscript for submission; Laure Wynants, Ben Van Calster and Dirk Timmerman had full access to all the data in the study and take responsibility for the integrity of the data and the accuracy of the data analysis.

Conflicts of Interest: The authors declare no conflict of interest.

\section{References}

1. Pavlik, E.J.; Ueland, F.R.; Miller, R.W.; Ubellacker, J.M.; DeSimone, C.P.; Elder, J.; Hoff, J.; Baldwin, L.; Kryscio, R.J.; van Nagell, J.R., Jr. Frequency and disposition of ovarian abnormalities followed with serial transvaginal ultrasonography. Obstet. Gynecol. 2013, 122, 210-217. [CrossRef] [PubMed]

2. Castillo, G.; Alcazar, J.L.; Jurado, M. Natural history of sonographically detected simple unilocular adnexal cysts in asymptomatic postmenopausal women. Gynecol. Oncol. 2004, 92, 965-969. [CrossRef] [PubMed]

3. Borgfeldt, C.; Andolf, E. Transvaginal sonographic ovarian findings in a random sample of women 25-40 years old. Ultrasound Obstet. Gynecol. 1999, 13, 345-350. [CrossRef] [PubMed]

4. Curtin, J.P. Management of the Adnexal Mass. Gynecol. Oncol. 1994, 55, S42-S46. [CrossRef] [PubMed]

5. Ferlay, J.; Steliarova-Foucher, E.; Lortet-Tieulent, J.; Rosso, S.; Coebergh, J.W.; Comber, H.; Forman, D.; Bray, F. Cancer incidence and mortality patterns in Europe: Estimates for 40 countries in 2012. Eur. J. Cancer 2013, 49, 1374-1403. [CrossRef] [PubMed]

6. Cancer Research UK. Available online: www.cancerresearchuk.org (accessed on 20 November 2016).

7. Vaughan, S.; Coward, J.I.; Bast, R.C., Jr.; Berchuck, A.; Berek, J.S.; Brenton, J.D.; Coukos, G.; Crum, C.C.; Drapkin, R.; Etemadmoghadam, D.; et al. Rethinking ovarian cancer: Recommendations for improving outcomes. Nat. Rev. Cancer 2011, 11, 719-725. [CrossRef] [PubMed]

8. Heintz, A.P.M.; Odicino, F.; Maisonneuve, P.; Quinn, M.A.; Benedet, J.L.; Creasman, W.T.; Ngan, H.Y.S.; Pecorelli, S.; Beller, U. Carcinoma of the Ovary. Int. J. Gynecol. Obstet. 2006, 95, S161-S192. [CrossRef]

9. Kobayashi, H.; Yamada, Y.; Sado, T.; Sakata, M.; Yoshida, S.; Kawaguchi, R.; Kanayama, S.; Shigetomi, H.; Haruta, S.; Tsuji, Y.; et al. A randomized study of screening for ovarian cancer: A multicenter study in Japan. Int. J. Gynecol. Cancer 2008, 18, 414-420. [CrossRef] [PubMed]

10. Buys, S.S. Effect of Screening on Ovarian Cancer Mortality. JAMA 2011, 305, 2295. [CrossRef] [PubMed]

11. Jacobs, I.J.; Menon, U.; Ryan, A.; Gentry-Maharaj, A.; Burnell, M.; Kalsi, J.K.; Amso, N.N.; Apostolidou, S.; Benjamin, E.; Cruickshank, D.; et al. Ovarian cancer screening and mortality in the UK Collaborative Trial of Ovarian Cancer Screening (UKCTOCS): A randomised controlled trial. Lancet 2016, 387, 945-956. [CrossRef]

12. Paulsen, T.; Kjaerheim, K.; Kaern, J.; Tretli, S.; Tropé, C. Improved short-term survival for advanced ovarian, tubal, and peritoneal cancer patients operated at teaching hospitals. Int. J. Gynecol. Cancer 2006, 16, 11-17. [CrossRef] [PubMed]

13. Engelen, M.J.; Kos, H.E.; Willemse, P.H.; Aalders, J.G.; de Vries, E.G.; Schaapveld, M.; Otter, R.; van der Zee, A.G. Surgery by consultant gynecologic oncologists improves survival in patients with ovarian carcinoma. Cancer 2006, 106, 589-598. [CrossRef] [PubMed] 
14. Earle, C.C.; Schrag, D.; Neville, B.A.; Yabroff, K.R.; Topor, M.; Fahey, A.; Trimble, E.L.; Bodurka, D.C.; Bristow, R.E.; Carney, M.; et al. Effect of surgeon specialty on processes of care and outcomes for ovarian cancer patients. J. Natl. Cancer Inst. 2006, 98, 172-180. [CrossRef] [PubMed]

15. Woo, Y.L.; Kyrgiou, M.; Bryant, A.; Everett, T.; Dickinson, H.O. Centralisation of services for gynaecological cancer-A Cochrane Systematic Review. Gynecol. Oncol. 2012, 126, 286-290. [CrossRef] [PubMed]

16. Valentin, L.; Hagen, B.; Tingulstad, S.; Eik-Nes, S. Comparison of "pattern recognition" and logistic regression models for discrimination between benign and malignant pelvic masses: A prospective cross validation. Ultrasound Obstet. Gynecol. 2001, 18, 357-365. [CrossRef] [PubMed]

17. Timmerman, D. The use of mathematical models to evaluate pelvic masses; can they beat an expert operator? Best Pract. Res. Clin. Obstet. Gynaecol. 2004, 18, 91-104. [CrossRef] [PubMed]

18. Meys, E.M.; Kaijser, J.; Kruitwagen, R.F.; Slangen, B.F.; van Calster, B.; Aertgeerts, B.; Verbakel, J.Y.; Timmerman, D.; van Gorp, T. Subjective assessment versus ultrasound models to diagnose ovarian cancer: A systematic review and meta-analysis. Eur. J. Cancer 2016, 58, 17-29. [CrossRef] [PubMed]

19. Timmerman, D.; Valentin, L.; Bourne, T.; Collins, W.P.; Verrelst, H.; Vergote, I. Terms, definitions and measurements to describe the sonographic features of adnexal tumors: A consensus opinion from the International Ovarian Tumor Analysis (IOTA) group. Ultrasound Obstet. Gynecol. 2000, 16, 500-505. [CrossRef] [PubMed]

20. Timmerman, D.; Testa, A.C.; Bourne, T.; Ameye, L.; Jurkovic, D.; van Holsbeke, C.; Paladini, D.; van Calster, B.; Vergote, I.; van Huffel, S.; et al. Simple ultrasound-based rules for the diagnosis of ovarian cancer. Ultrasound Obstet. Gynecol. 2008, 31, 681-690. [CrossRef] [PubMed]

21. Royal College of Obstetricians and Gynaecologists. Management of Suspected Ovarian Masses in Premenopausal Women; Green-top Guideline No. 62; Royal College of Obstetricians and Gynaecologists: London, UK, 2011.

22. The American College of Obstetricians and Gynecologists. Practice bulletin-Evaluation and Management of Adnexal Masses. Obstet. Gynecol. 2016, 128, e210-e226.

23. Kaijser, J.; Sayasneh, A.; van Hoorde, K.; Ghaem-Maghami, S.; Bourne, T.; Timmerman, D.; van Calster, B. Presurgical diagnosis of adnexal tumours using mathematical models and scoring systems: A systematic review and meta-analysis. Hum. Reprod. Update 2014, 20, 449-462. [CrossRef] [PubMed]

24. Timmerman, D.; van Calster, B.; Testa, A.; Savelli, L.; Fischerova, D.; Froyman, W.; Wynants, L.; van Holsbeke, C.; Epstein, E.; Franchi, D.; et al. Predicting the risk of malignancy in adnexal masses based on the Simple Rules from the International Ovarian Tumor Analysis group. Am. J. Obstet. Gynecol. 2016, 214, 424-437. [CrossRef] [PubMed]

25. Van Calster, B.; van Hoorde, K.; Valentin, L.; Testa, A.C.; Fischerova, D.; van Holsbeke, C.; Savelli, L.; Franchi, D.; Epstein, E.; Kaijser, J.; et al. International Ovarian Tumour Analysis, G. Evaluating the risk of ovarian cancer before surgery using the ADNEX model to differentiate between benign, borderline, early and advanced stage invasive, and secondary metastatic tumours: Prospective multicentre diagnostic study. BMJ 2014, 349, g5920. [CrossRef] [PubMed]

26. Meys, E.M.; Jeelof, L.S.; Achten, N.M.; Slangen, B.F.; Lambrechts, S.; Kruitwagen, R.F.; van Gorp, T. Estimating the risk of malignancy in adnexal masses: An external validation of the ADNEX model and comparison with other frequently used ultrasound methods. Ultrasound Obstet. Gynecol. 2016. [CrossRef] [PubMed]

27. Sayasneh, A.; Ferrara, L.; de Cock, B.; Saso, S.; Al-Memar, M.; Johnson, S.; Kaijser, J.; Carvalho, J.; Husicka, R.; Smith, A.; et al. Evaluating the risk of ovarian cancer before surgery using the ADNEX model: A multicentre external validation study. Br. J. Cancer 2016, 115, 542-548. [CrossRef] [PubMed]

28. Szubert, S.; Wojtowicz, A.; Moszynski, R.; Zywica, P.; Dyczkowski, K.; Stachowiak, A.; Sajdak, S.; Szpurek, D.; Alcazar, J.L. External validation of the IOTA ADNEX model performed by two independent gynecologic centers. Gynecol. Oncol. 2016, 142, 490-495. [CrossRef] [PubMed]

29. Araujo, K.G.; Jales, R.M.; Pereira, P.N.; Yoshida, A.; de Angelo Andrade, L.; Sarian, L.O.; Derchain, S. Performance of the IOTA ADNEX model in the preoperative discrimination of adnexal masses in a gynecologic oncology center. Ultrasound Obstet. Gynecol. 2016. [CrossRef]

30. Joyeux, E.; Miras, T.; Masquin, I.; Duglet, P.E.; Astruc, K.; Douvier, S. Before surgery predictability of malignant ovarian tumors based on ADNEX model and its use in clinical practice. Gynecol. Obstet. Fertil. 2016, 44, 557-564. [CrossRef] [PubMed] 
31. Testa, A.; Kaijser, J.; Wynants, L.; Fischerova, D.; van Holsbeke, C.; Franchi, D.; Savelli, L.; Epstein, E.; Czekierdowski, A.; Guerriero, S.; et al. Strategies to diagnose ovarian cancer: New evidence from phase 3 of the multicentre international IOTA study. Br. J. Cancer 2014, 111, 680-688. [CrossRef] [PubMed]

32. DeLong, E.R.; DeLong, D.M.; Clarke-Pearson, D.L. Comparing the areas under two or more correlated receiver operating characteristic curves: A nonparametric approach. Biometrics 1988, 44, 837-845. [CrossRef] [PubMed]

33. Wilson, E.B. Probable inference, the law of succession, and statistical inference. J. Am. Stat. Assoc. 1927, 22, 209-212. [CrossRef]

34. Collins, G.S.; Reitsma, J.B.; Altman, D.G.; Moons, K.G. Transparent reporting of a multivariable prediction model for individual prognosis or diagnosis (TRIPOD): The TRIPOD statement. BMJ 2015, 350, g7594. [CrossRef] [PubMed]

35. Hartman, C.A.; Juliato, C.R.; Sarian, L.O.; Toledo, M.C.; Jales, R.M.; Morais, S.S.; Pitta, D.D.; Marussi, E.F.; Derchain, S. Ultrasound criteria and CA 125 as predictive variables of ovarian cancer in women with adnexal tumors. Ultrasound Obstet. Gynecol. 2012, 40, 360-366. [CrossRef] [PubMed]

36. Alcazar, J.L.; Pascual, M.A.; Olartecoechea, B.; Graupera, B.; Auba, M.; Ajossa, S.; Hereter, L.; Julve, R.; Gaston, B.; Peddes, C.; et al. IOTA simple rules for discriminating between benign and malignant adnexal masses: Prospective external validation. Ultrasound Obstet. Gynecol. 2013, 42, 467-471. [CrossRef] [PubMed]

37. Sayasneh, A.; Wynants, L.; Preisler, J.; Kaijser, J.; Johnson, S.; Stalder, C.; Husicka, R.; Abdallah, Y.; Raslan, F.; Drought, A.; et al. Multicentre external validation of IOTA prediction models and RMI by operators with varied training. Br. J. Cancer 2013, 108, 2448-2454. [CrossRef] [PubMed]

38. Nunes, N.; Ambler, G.; Foo, X.; Naftalin, J.; Widschwendter, M.; Jurkovic, D. Use of IOTA simple rules for diagnosis of ovarian cancer: Meta-analysis. Ultrasound Obstet. Gynecol. 2014, 44, 503-514. [CrossRef] [PubMed]

39. Tinnangwattana, D.; Vichak-ururote, L.; Tontivuthikul, P.; Charoenratana, C.; Lerthiranwong, T.; Tongsong, T. IOTA Simple Rules in Differentiating between Benign and Malignant Adnexal Masses by Non-expert Examiners. Asian Pac. J. Cancer Prev. 2015, 16, 3835-3838. [CrossRef] [PubMed]

40. Ruiz de Gauna, B.; Rodriguez, D.; Olartecoechea, B.; Auba, M.; Jurado, M.; Gomez Roig, M.D.; Alcazar, J.L. Diagnostic performance of IOTA simple rules for adnexal masses classification: A comparison between two centers with different ovarian cancer prevalence. Eur. J. Obstet. Gynecol. Reprod. Biol. 2015, 191, 10-14. [CrossRef] [PubMed]

41. Knafel, A.; Banas, T.; Nocun, A.; Wiechec, M.; Jach, R.; Ludwin, A.; Kabzinska-Turek, M.; Pietrus, M.; Pitynski, K. The Prospective External Validation of International Ovarian Tumor Analysis (IOTA) Simple Rules in the Hands of Level I and II Examiners. Ultraschall Med. 2015, 37, 516-523. [CrossRef] [PubMed]

42. Shih, I.-M.; Kurman, R. Ovarian Tumorigenesis-A Proposed Model Based on Morphological and Molecular Genetic Analysis. Am. J. Pathol. 2004, 164, 1511-1518. [CrossRef]

43. Valentin, L.; Ameye, L.; Jurkovic, D.; Metzger, U.; Lecuru, F.; van Huffel, S.; Timmerman, D. Which extrauterine pelvic masses are difficult to correctly classify as benign or malignant on the basis of ultrasound findings and is there a way of making a correct diagnosis? Ultrasound Obstet. Gynecol. 2006, 27, 438-444. [CrossRef] [PubMed]

44. Valentin, L.; Ameye, L.; Savelli, L.; Fruscio, R.; Leone, F.P.; Czekierdowski, A.; Lissoni, A.A.; Fischerova, D.; Guerriero, S.; van Holsbeke, C.; et al. Adnexal masses difficult to classify as benign or malignant using subjective assessment of gray-scale and Doppler ultrasound findings: Logistic regression models do not help. Ultrasound Obstet. Gynecol. 2011, 38, 456-465. [CrossRef] [PubMed]

45. Vergote, I.; Amant, F.; Ameye, L.; Timmerman, D. Screening for ovarian carcinoma: Not quite there yet. Lancet Oncol. 2009, 10, 308-309. [CrossRef]

46. Fischerova, D.; Zikan, M.; Dundr, P.; Cibula, D. Diagnosis, treatment, and follow-up of borderline ovarian tumors. Oncologist 2012, 17, 1515-1533. [CrossRef] [PubMed]

47. Vergote, I.; de Brabander, J.; Fyles, A.; Bertelsen, K.; Einhorn, N.; Sevelda, P.; Gore, M.; Kaern, J.; Verrelst, H.; Sjövall, K.; et al. Prognostic importance of degree of differentiation and cyst rupture in stage I invasive epithelial ovarian carcinoma. Lancet 2001, 357, 176-182. [CrossRef]

48. Ledermann, J.A.; Raja, F.A.; Fotopoulou, C.; Gonzalez-Martin, A.; Colombo, N.; Sessa, C.; Group, E.G.W. Newly diagnosed and relapsed epithelial ovarian carcinoma: ESMO Clinical Practice Guidelines for diagnosis, treatment and follow-up. Ann. Oncol. 2013, 24 (Suppl. S6), vi24-vi32. [CrossRef] [PubMed] 
49. Kurman, R.J.; Shih, I.-M. Molecular pathogenesis and extraovarian origin of epithelial ovarian cancer-Shifting the paradigm. Hum. Pathol. 2011, 42, 918-931. [CrossRef] [PubMed]

50. Amant, F.; Verheecke, M.; Wlodarska, I.; Dehaspe, L.; Brady, P.; Brison, N.; van Den Bogaert, K.; Dierickx, D.; Vandecaveye, V.; Tousseyn, T.; et al. Presymptomatic Identification of Cancers in Pregnant Women During Noninvasive Prenatal Testing. JAMA Oncol. 2015, 1, 814-819. [CrossRef] [PubMed]

51. Vanderstichele, A.; Busschaert, P.; Smeets, D.; Landolfo, C.; van Nieuwenhuysen, E.; Leunen, K.; Neven, P.; Amant, F.; Mahner, S.; Braicu, E.I.; et al. Chromosomal Instability in Cell-Free DNA as a Highly Specific Biomarker for Detection of Ovarian Cancer in Women with Adnexal Masses. Clin. Cancer Res. 2016. [CrossRef] [PubMed]

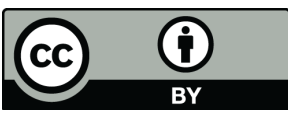

(C) 2017 by the authors. Licensee MDPI, Basel, Switzerland. This article is an open access article distributed under the terms and conditions of the Creative Commons Attribution (CC BY) license (http:/ / creativecommons.org/licenses/by/4.0/). 